\title{
Ex vivo detection and quantification of apically extruded volatile compounds and disinfection by-products by SIFT-MS, during chemomechanical preparation of infected root canals
}

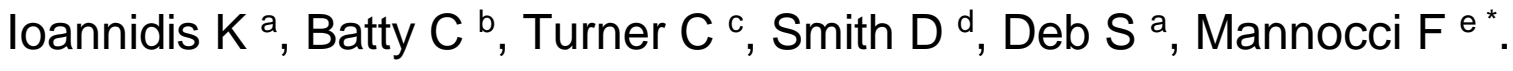

a Centre for Oral Clinical \& Translational Science, Faculty of Dentistry, Oral \& Craniofacial Sciences, Floor 17, Tower Wing, Guy's Hospital, London Bridge, SE1 9RT, King's College London, London, United Kingdom.

b School of Life, Health and Chemical Sciences, The Open University, MK7 6AA, Milton Keynes, United Kingdom.

${ }^{c}$ College of Health and Life Sciences, Brunel University, UB8 3PH, Uxbridge, London, United Kingdom

d Transspectra Limited, ST5 8RP, Newcastle Under Lyme, UK.

e Department of Endodontology, Faculty of Dentistry, Oral \& Craniofacial Sciences, SE1 9RT, King's College London, London, United Kingdom.

*: corresponding author

E-mail address: francesco.mannocci@kcl.ac.uk (F. Mannocci)

\section{Keywords:}

chloroform; disinfection by-products; edta; endodontics; formaldehyde; irrigation; root canal; selected ion flow tube mass spectrometry; volatile compounds

\section{Declarations of competing interests: None}

The authors deny any conflict of interest

This research did not receive any specific grant from funding agencies in the public, commercial, or notfor-profit sectors. 


\section{Introduction}

Sodium hypochlorite $(\mathrm{NaOCl})$ is one of the of the most widely practised public health components of water disinfection to prevent the spread of microbial or viral diseases and contamination [1,2]. Despite its importance, chlorination of water for disinfection purposes may result in the formation of potentially harmful halogenated disinfection by-products (DBPs), due to the reaction of chlorine or hypochlorite with natural organic matter (NOM) [3]. In the presence of DBPs, daily exposure to chlorinated water via inhalation, drinking, dermal absorption through bathing, showering and swimming [4], may be dangerous to human health because of the carcinogenic and mutagenic properties of these DBP compounds $[5,6]$.

The use of $\mathrm{NaOCl}$ has been universally adopted in endodontics as the main irrigant for the disinfection of infected root canals [7]. A consensus exists that a concentration of $2.5 \% \mathrm{NaOCl}$ is clinically acceptable both in terms of antimicrobial and dissolution capacity in Endodontics [8]. The use of a chelating agent, such as $17 \%$ EDTA, aids in the removal of the infected inorganic components of the forming smear layer, during root canal instrumentation [9].

One of the side effects of the chemical interactions of $\mathrm{NaOCl}$, which has received relatively little attention in the dental literature, is the formation of harmful volatile organic compounds (VOCs) and chlorinated disinfection by-products (DBPs). Varise et al., reported the detection of organochlorine compounds including chloroform, hexachloroethane, dichloromethylbenzene and benzaldehyde, after 15 -min interaction of $0.5 \%, 2.5 \%, 5.25 \% \mathrm{NaOCl}$ with bovine dentine powder and pulp tissue fragments, using gas chromatography-mass spectrometry (GC-MS) [10]. A recent study by loannidis et al. showed that the 30 -min chemical interaction of $2.5 \% \mathrm{NaOCl}$ with combined sources of infected root canal content including dentine powder, planktonic multi-microbial suspensions and bovine serum albumin resulted in the formation of increased levels of toxic VOCs and DBPs, such as ammonia, acetaldehyde, ethanol, acetonitrile and chloroform, with the aid of selected ion flow tube mass spectrometry (SIFTMS) [11]. The emergence of toxic VOCs and chlorinated DBPs from the interaction of $\mathrm{NaOCl}$ with infected root canal content requires further examination due to the potential hazardous drawbacks during root canal preparation and irrigation.

The risk of debris extrusion into the periradicular tissues through the apical foramen, during chemomechanical preparation of the root canals is a reality, even under conditions of strict control of 
the root canal length and good clinical practice [12]. Hülsmann et al. stated that, in any endodontic treatment, an instrument used in an apical direction or an instrument acting as a plunger may result in periapical extrusion of root canal biomass [13]. $\mathrm{NaOCl}$ has gained significant attention due to its relatively high toxicity in contact with periapical tissues, even in a low-scale exposure in terms of time, quantity and concentration [14,15]. However, apart from $\mathrm{NaOCl}$, any source of combined chemical, physical, mechanical, microbial irritation has a potential to disrupt the integrity and balance of periradicular tissues, leading to the induction of periapical inflammatory response [16]. From a clinical point of view, the occurrence of apical extrusion in root canal procedures may predispose the occurrence of inter-appointment flare ups, post-operative pain, extra-radicular infection and delayed healing response $[16,17]$.

$\mathrm{NaOCl}$ is a strong oxidising agent and interacts with the infected content of the root canal system, whilst instrumentation progresses and irrigation depth increases. Disrupted microbial biofilms, vital or necrotic cells, blood and plasma exudates, vital or necrotic pulp remnants comprise this multivariable content and provide a constant reservoir of natural organic matter (NOM), exposed to replenishing volumes of $\mathrm{NaOCl}$ [18]. The forming post-chlorinated biomass may potentially extrude through the root apex during root canal chemomechanical preparation. Hence, any forming VOCs and chlorinated DBPs may penetrate and leak through the apical foramen, biologically interact with periapical tissues and flow through blood circulation. However, the identification and quantification of VOCs and chlorinated DBPs as well as the risk of extrusion in the periradicular space have not yet been elucidated.

The aim of this study was to screen and quantify ex vivo, the formation and extrusion of VOCs and chlorinated DBPs in periradicular space, following the clinical simulation of instrumentation and irrigation of infected root canal specimens, with rotary NiTi insturments, $2.5 \% \mathrm{NaOCl}$ and $17 \%$ EDTA. The null hypothesis was that the chemomechanical preparation of ex vivo infected root canals did not result in the formation and extrusion of VOCs and chlorinated DBPs. 


\section{Materials and Methods}

\subsection{Sample size calculation}

A two-way repeated measures experimental design was employed. Sample size estimation was conducted a priori with G*Power 3.1.9.2 software (Franz Faul, Universitaet Kiel, Germany). To ensure that a standardized effect of size 0.23 would be detected by two-way ANOVA at $80 \%$ power and with a probability of alpha-type error of 0.05 , a sample size of 42 specimens was required for three experimental groups $(n=3 \times 14)$. To compensate for uncertainty in these assumptions, 4 additional specimens were added in each group, resulting in a total of 54 human single-rooted teeth for use in the study.

\subsection{Specimen selection and preparation}

Fifty-four ( $\mathrm{N}=54)$ freshy extracted single rooted teeth with a single round canal, that were free of cracks, fractures, caries, external cervical root resorption, abrasions and discolouration were collected. Informed and written consent was obtained by medically-fit patients, who were referred by their dentists to have their teeth extracted in dental surgery premises. The collection and specimen storage procedures were approved and conducted in accordance with the protocol outlined by the Research Ethical Committee (Wales REC 4, 14/WA/1004, UK).

All specimens were soaked into $0.5 \% \mathrm{NaOCl}$ for $60 \mathrm{~min}$ to remove soft tissue and root surfaces were polished with elastic pumices. The crowns of the teeth were removed with a wafering blade and the length of each root specimen was standardised to $15 \mathrm{~mm}$. Digital radiographs (Digora Optime, Acteon, UK) were taken in buccal and proximal directions. Radiographic criteria for tooth selection were the presence of a single canal, root curvature $<10^{\circ}$, no signs of internal and external apical root resorption or calcification and a fully developed apex.

To ensure apical patency, a sterile size $8 \mathrm{~K}$-file (Dentsply Sirona, Switzerland) was initially placed $1 \mathrm{~mm}$ beyond the foramen. The working length of each specimen was determined by apical insertion of a size $10 \mathrm{~K}$-file (Dentsply Sirona, Switzerland) in the canal until its tip was detected through apical foramen, followed by $1 \mathrm{~mm}$ subtraction. All procedures were carried out under magnification with a dental operating microscope (Global Surgical Corporation, USA). The root canals were initially prepared 
up to working length, with ProTaper Universal (Dentsply Sirona, Switzerland) rotary files S1, S2 and F1. Irrigation was performed with $5.25 \% \mathrm{NaOCl}$ (Chloraxid, Cerkamed, $\mathrm{PL}$ ) using a total volume of $6 \mathrm{ml}$ (2ml per file sequence). The prepared root canals were flushed with $2 \mathrm{ml}$ distilled water and $2 \mathrm{ml} 17 \%$ EDTA (Schottlander \& Davis Ltd, UK) were used to remove the inorganic phase of the smear layer. A final flush with $2 \mathrm{ml}$ distilled water was performed to remove any irrigant residues and the canals were dried with sterile paper points (Size F1, Dentsply Sirona, Switzerland).

\subsection{Fabrication of testing apparatus}

A novel testing apparatus was fabricated to simulate the conditions of mechanical preparation and intracanal irrigation in a 'water-closed' apical system, to reflect periapical tissue resistance to irrigant extrusion and simulate high- compliance periapical lesions [19]. A mini zinc plated fuel hose line clamp (diameter: 11-13 mm, height: $10 \mathrm{~mm}$ ) (Wilson Lendrum \& Weir Ltd, Northern Ireland, UK) was initially adjusted and fitted $2 \mathrm{~mm}$ in depth ( $1 / 5$ of actual height) to the external diameter $(11.5-12 \mathrm{~mm})$ of the open end of a 4-mL clear glass bottle (Ampulla Ltd, Cheshire, UK) (Fig. 1a).

Each root specimen was vertically stabilised on its coronal surface with thermo-plasticised silicon glue with the aid of a glue gun (Bosch PKP $18 \mathrm{E}$, Robert Bosch Holdings, UK). Every clamp was positioned in the periphery of each root to achieve a centering position of specimen within the diameter of the clamp margins. The clamp was then filled with same type injectable thermo-plasticised silicon glue and glue gun (Bosch PKP 18 E, Robert Bosch Holdings, UK). The root specimen was covered up to apical third by silicon glue which was cylindrically shaped after application of vertical pressure with the aid of each 4-ml clear glass bottle (Fig. 1b-d). The apical 3mm remained exposed within the boundaries of the glass vial. The testing apparatus consisted of two elements: The silicon-infused clamp, as a representative mold of the external surface of each root specimen, and the selected 4-ml glass vial. The clamp was tightened with the aid of an electric screwdriver (Bosch IXO, Robert Bosch Holdings Ltd, UK), to ensure the performance of the apparatus as a single unit. Once materials set, the root specimen was removed and the apparatus was inspected to ensure that no structural deficiencies were evident. Prior to use, every surface of the testing apparatus elements was sterilised under UV irradiation for $2 \mathrm{~h}$. 


\subsection{Development of nutrient-stressed multispecies biofilm within root specimens}

A stressed multispecies biofilm comprising five selected bacteria was developed on the root canal of each selected hemi section using the protocol developed by Niazi et al. [20]. The selected endodontic bacteria in this biofilm included Propionibacterium acnes, Actinomyces radicidentis, Staphylococcus epidermidis, Streptococcus mitis -recovered from root canals of teeth with refractory endodontic infections- and Enterococcus faecalis strain OMGS 3202 [21,22].

To establish the biofilms, the strains were cultured anaerobically at $37^{\circ} \mathrm{C}$ for seven days on Fastidious Anaerobe Agar supplemented with 5\% defibrinated horse blood (FAA, Thermo Scientific ${ }^{\mathrm{TM}}$, UK). Individual starter cultures of each species were collected with inoculation loops (Cole-Palmer, UK), added in filter-sterilized modified fluid universal medium (mFUM) and incubated at $37^{\circ} \mathrm{C}$ for $3 \mathrm{~h}$ in anaerobic workstation (MACS-MG-1000, Don Whitley Scientific Ltd, UK) [23]. The absorbance was adjusted with fresh mFUM to 0.5 at $540 \mathrm{~nm}$ to obtain $10^{7} \mathrm{cells} / \mathrm{ml}$ per specie (Labsystems iEMS Reader MF, Basingstoke, UK).

The prepared root specimens were autoclaved at $121^{\circ} \mathrm{C}$ for $15 \mathrm{~min}$ and placed in sterile $2 \mathrm{ml}-$ containing Eppendorf safe-lock tubes (Eppendorf UK Ltd, Stevenage, UK). The root canals and the tubes were filled with mFUM and pre-reduced in an anaerobic atmosphere (80\% nitrogen, $10 \%$ hydrogen and $10 \%$ carbon dioxide) for $2 \mathrm{~h}$ and then mFUM was aspirated. Six, randomly selected, sterile root specimens remained in mFUM, without microbial inoculation to confirm sterility and no biofilm growth.

The root canals of the remaining 48 specimens were filled to the orifice level with a suspension, containing a mixture of the five microbial species of equal volume and adjusted absorbance, with the aid of sterile 1-ml insulin syringes with a 30-G needle (Medisave Ltd, UK). Prior to incubation, the canals were gently hand-instrumented with a sterile $15 \mathrm{~K}$-file (Dentsply Sirona, Switzerland) up to working length to carry the bacteria down to the length of the canals. The Eppendorf safe-lock tubes were then re-filled with mFUM. The biofilms were grown anaerobically with regular medium change after every 24 $\mathrm{h}$, for the first 7 days. In the next 7 days, the biofilms were left to grow in the same unchanged medium in order to stress microorganisms nutritionally [20]. After a total period of 14 days, the 48 biofilmcontaining root specimens were prepared for assignment to one control and two experimental groups ( $n=16$ specimens/group). 


\subsection{Examination of biofilm development}

After the 14-day period, the six sterile root specimens (no biofilm growth) and six -randomly selected- inoculated root specimens (two per group; biofilm growth) were prepared for scanning electron microscopy (SEM) and confocal laser scanning microscopy (CLSM) examination. A low-speed abrasive diamond disc was used to cut a groove along the long axis of each specimen without reaching the root canal system (TOC, Bristol, UK) [24]. A chisel (Draper Tools Ltd, Hampshipe, UK) was then used to split the tooth open into two pieces [25]. These procedures were performed in a Class II laminar flow biological safety cabinet (Nuaire, USA), to avoid cross-contamination of the specimens.

For SEM imaging, the dissected specimens were immediately fixed in phosphate-buffered formalin 10\%, dehydrated in ethanol and dried in hexamethyldisilazane (HMDS) (Agar Scientific, Stansted, UK) [26]. The specimens were gold sputter coated (Polaron E5100; Quorum Technologies, Ringmer, UK) and used for SEM examination (JCM-6000PLUS NeoScope Benchtop SEM, Jeol, USA) to confirm the absence / establishment of the biofilm, at a magnification of $x 500-x 2000$, operating at $10 \mathrm{kV}$.

For CLSM imaging, the biofilms were stained with a Live/Dead Baclight bacterial viability kit (Thermofisher Scientific, UK) and visualized under a Leica TCS SP2 confocal laser scanning microscope (Leica Microsystems, Milton Keynes, UK). A x63 magnification oil immersion objective with a numerical aperture of 1.40 , and a confocal pinhole to Airy 1 unit was used to observe the fluorescence emission of SYTO® 9 and Propidium lodide using $488 \mathrm{~nm}$ and $569 \mathrm{~nm}$ (Ar-Kr laser) as the excitation source, respectively. Image acquisition was performed with a zoom factor of 4.0, a pixel resolution of $0.11 \mu \mathrm{m} /$ pixel and field resolution of $512 \times 512$ pixels.

\subsection{Protocols of chemomechanical preparation procedures}

After 14 days, the root specimens were removed from the inoculation tubes and had their external root surfaces dried with sterile gauzes. Then, they were transferred into their assigned silicon indices. The glass vials were filled with $4 \mathrm{ml}$ sterile ultrapure water (Simplicity UV Milipore SAS, France), merged with the clamps and tightened with the aid of an electric screwdriver (Bosch IXO, Robert Bosch 
Holdings, UK), to ensure the performance of the apparatus as a single unit. A PTFE white thread tape (0.075mm thickness) (RS Pro, UK) was further adjusted around their external interface to ensure airtight marginal adaptation, further sustainability of a 'water-closed' periradicular system and maintenance of apical pressure (no pressure equalisation). The glass vials were also coated with a brown packing tape (Packatape, UK) to ensure no visualization of the root apex and the periradicular space by the operator.

The remaining 42 infected root specimens were randomly divided into 3 Groups ( $n=3 \times 14)$, using a software (List Randomiser; https://www.random.org/lists/). In Group 1, no endodontic intervention was performed. Groups 2 and 3 were the experimental groups, in which endodontic intervention was performed. All procedures were performed in a Class II laminar flow biological safety cabinet (Nuaire, USA), to prevent cross-contamination of the specimens.

Mechanical root preparation was performed with the use of rotary files Protaper Gold Universal instruments F1, F2 and F3 (Dentsply Maillefer, Switzerland). The files were connected with a 6:1 contraangle hand-piece in an endodontic-motor (X-Smart Plus Endo Motor, Dentsply Maillefer, Switzerland), set at speed $=300 \mathrm{rpm}$ and torque $=3 \mathrm{Ncm}^{-1}$. Each file was used in a crown-down manner, with in-and-out brushing motion against all root canal walls, gradually progressing at full working length, after 30 s of use. The irrigants used were sterile saline ( $\mathrm{NaCl} 0.9 \%$ ) (JFA Medical, Blackpool, UK), $2.5 \% \mathrm{NaOCl}$ and 17\% EDTA (Schottlander \& Davis, Letchworth Garden City, UK). Concentrated NaOCl solution was prepared from a stock solution $\mathrm{NaOCl} \geq 10 \%$ (Sigma Aldrich, Gillingham, UK) and verified with a standard iodine/thiosulfate method (iodometric titration) [11]. Syringe irrigation was performed using a 27-Gauge, open-ended needle and a 3-ml containing syringe with a luer-lock (Monoject, Medtronic, UK). A rubber-stop was applied on the needle, 3mm short of working length. Irrigation was carried out by using digital pressure with the forefinger only at an estimated flow rate $3 \mathrm{ml} / \mathrm{min}$. The needle was gently moved up and down in a $2 \mathrm{~mm}$ range, ensuring that it did not bind on axial walls.

Ultrasonically activated irrigation (UAl) was performed with the application of a size 25 and zero taper ultrasonic file (Irrisafe, Acteon, UK) in the root canals filled with irrigant. The ultrasonic unit (Newtron Booster, Acteon, UK) was adjusted for endodontic use (ring colour at yellow) with a power setting at 9 , according to the manufacturer's instructions. The file was inserted into the canal $1 \mathrm{~mm}$ short of working length. 
As previously stated, Group $1(n=14)$ received no endodontic intervention. The chemomechanical preparation in Groups 2 and 3 was performed by an accredited Specialist Endodontist (K.I.). The sequence of instrumentation and irrigation procedures for Groups 2 and 3 is described in Figure 2 and briefly summarized below:

- Group $2(\mathrm{n}=14)$ : Protaper $\mathrm{F} 1+3 \mathrm{ml}$ saline, Protaper $\mathrm{F} 2+3 \mathrm{ml}$ saline, Protaper $\mathrm{F} 3+7 \mathrm{ml}$ saline, $1 \mathrm{ml}$ saline+UAI.

- Group $3(\mathrm{n}=14)$ : Protaper $\mathrm{F} 1+3 \mathrm{ml} 2.5 \% \mathrm{NaOCl}$, Protaper $\mathrm{F} 2+3 \mathrm{ml} 2.5 \% \mathrm{NaOCl}$, Protaper $\mathrm{F} 3+3 \mathrm{ml}$ $2.5 \% \mathrm{NaOCl}, 1 \mathrm{ml}$ saline / $2 \mathrm{ml} 17 \%$ EDTA / $1 \mathrm{ml}$ saline, $1 \mathrm{ml} 2.5 \% \mathrm{NaOCl} / \mathrm{UAI}$.

During irrigation, a portable medical suction unit (Armoline, Medical Import Ltd, London, UK) was used to aspirate the effluent from the prepared root canals, with the aid of a sterile silicon tube (external diameter: 10mm; Wall Thickness: 2mm) (Ad Fontes Company Ltd, Hong Kong) (Fig. 3a). The use of dental suction was contributory to the simulation of clinical conditions and standards of good endodontic practice.

\subsection{Collection of aliquots}

Once chemomechanical procedures were complete, the clamp-silicon-specimen apparatus was untightened from the glass vial. The liquid content $(4 \mathrm{ml})$ of the 'water-closed' periradicular space obtained from Groups 1, 2 and 3 (Fig. 3b) was dispersed in sterile polystyrene bijou containers (Sterilin, Thermo Scientific ${ }^{\mathrm{TM}}$, UK) and kept refrigerated at $-80^{\circ} \mathrm{C}$ until analysis

In order to obtain a better knowledge of all possible occurring chemical interactions, we also mixed $1 \mathrm{ml} \mathrm{NaOCl} 2.5 \%$ with $1 \mathrm{ml}$ EDTA $17 \%$, obtained from 5 different commercially available brands for dental use. The aliquots were stirred for $3 \mathrm{~min}$ and kept refrigerated at $-80^{\circ} \mathrm{C}$ until analysis.

\subsection{SIFT-MS analysis}

The SIFT-MS technique has been extensively described elsewhere [27]; however, a brief explanation is warranted here. In SIFT-MS, a mixture of reagent ions $\left(\mathrm{H}_{3} \mathrm{O}_{+}, \mathrm{NO}+\right.$ and $\left.\mathrm{O}_{2}+\right)$ are generated in a microwave discharge through humid air. Each of these reagent ions can be selected by 
a quadrupole mass filter and separately injected into a fast-flowing helium carrier gas in a flow tube at a pressure of typically 1 mbar. The sample gas to be analysed naturally flows into the helium at a controlled rate via a heated calibrated capillary by virtue of the atmospheric pressure of the sample gas and the much lower pressure of the helium (typically $1 \mathrm{mbar}$ ). The chosen reagent ion species then reacts with the trace components in the sample gas (to the exclusion of the major air components) to generate product (analyte) ions. The reagent ions and analyte ions are mass analysed by a quadrupole mass spectrometer and counted by a detector. Thus, the characteristic analyte ions identify the neutral trace components present in the sample and their count rates provide their concentrations in real time.

The SIFT-MS instrument may be operated in two modes: the scan mode where a whole spectrum is captured over a desired mass-to-charge $(\mathrm{m} / \mathrm{z})$ ration range, or a selected ion mode, where individual analyte ions are targeted and counted individually. The former is ideal for identifying compounds of interest; the latter produces more accurate quantification. Both modes were used in this study, but quantification was carried out using the selected ion mode.

For analysis, the samples were defrosted in air. Analysis of the headspace volatile compounds was carried out in real-time by SIFT-MS. Prior to analysis, three replicate $1 \mathrm{ml}$ aliquots of each sample were placed into a sample bag constructed from $50 \mathrm{~cm}$ length, $65 \mathrm{~mm}$ diameter Nalophan NA (Kalle, UK), which was then filled with purified air and sealed prior to incubation at $37^{\circ} \mathrm{C}$. After equilibration between the liquid and its headspace (30min), the headspace was sampled directly into the SIFT-MS via a heated, calibrated capillary that defines the headspace sample flow rate, as is necessary for absolute quantification of VOCs. The analytical downstream quadrupole mass spectrometer was scanned over the range of $\mathrm{m} / \mathrm{z}$ using the three reagent ions $\mathrm{H}_{3} \mathrm{O}^{+}, \mathrm{NO}^{+}$and $\mathrm{O}_{2}+$ independently. From the spectra, individual neutral compounds were identified by their characteristic analyte ions. From the $\mathrm{m} / \mathrm{z}$ values of the analyte ions and their count rates, and using the kinetics database stored in the instrument library, the concentrations of the identified VOCs were immediately obtained $[27,28]$.

\subsection{Statistical Analysis}

Two-way analysis of variance (ANOVA) with post hoc Tukey tests was used for data analysis of the forming VOCs and DBPs from the periradicular space and the effluent solutions. The overall 
analysis was performed with SPSS software (version 22.0, IBM SPSS Inc., Chicago, IL, USA). The level of statistical significance was set at $\mathrm{P}<0.05$.

\section{Results}

\subsection{Biofilm growth in root specimens}

The examination of the infected tooth specimens with SEM and CLSM confirmed the presence of a thick biofilm layer, attached on the main canal lumen as well as extending within dentine tubules (Fig. 4a-d). The images obtained from confocal analysis, confirmed the presence of live microbial cells (green) as a major proportion of the grown biofilm, as well as minor proportions of dead microbial cells (red), as a sequence of biofilm metabolic process (Fig. 4b, 4d). On the contrary, the examination of the sterile tooth specimens showed the presence of open dentine tubules and confirmed the absence of microbial populations (Fig. 4e, 4f).

\subsection{SIFT-MS analysis of aliquots following NaOCI-EDTA interaction}

The interaction of $17 \%$ EDTA of five different brands with $2.5 \% \mathrm{NaOCl}$ resulted in the unexpected generation of large quantities of detectable formaldehyde (Table 1). The production of formaldehyde can be inferred from the observed ion chemistry, which is described in a previous study by Spaněl et al. [29]. Furthermore, there was a strong odour of formaldehyde emanating from the samples with high concentrations. The visual assessment of the mixed solutions disclosed that colour transition from transparent to brown occurred in Schottlander EDTA, with possible precipitate formation, which was not visually evident (Fig. 5a). The interaction of ENDO-solution and $\mathrm{NaOCl}$ resulted in complete loss of transparency and the solutions presented a greyish foggy colour (Fig. 5b). The interaction of SmearClear and TGcleanser with $\mathrm{NaOCl}$ resulted in gas generation and pronounced bubble formation (Fig. 5c, 5d). Finally, the interaction of Pulpdent and $\mathrm{NaOCl}$ did not result in any colour change (Fig. 5e). On the contrary, all available solutions of sole 17\% EDTA presented low counts of formaldehyde, close to the detection limit for positive identification of formaldehyde by the current SIFTMS instrument (Table 1). 


\subsection{SIFT-MS analysis of aliquots from periradicular space / Apical extrusion}

The headspace of all samples contained several common compounds that are often seen in biological media headspace, including acetone, acetic acid, methanol, ethanol, propanol, acetaldehyde, acetonitrile and ammonia (Table 2) [30]. The concentration of all compounds in Group 2 were detectable but at a very low concentrations in the parts-per-billion by volume (ppbv) range. In Group 3, the concentration of all compounds, except for ethanol, were present at much higher concentrations, as can be seen by the very busy spectra shown in Figures 6 and 7 . The pronounced peak at $\mathrm{m} / \mathrm{z} 31$ in Figure 6 is due to formaldehyde and the 3 peaks at $\mathrm{m} / \mathrm{z} 83,85$ and 87 in Figure 7 are the isotopologues of chloroform $[27,29]$. These compounds are at statistically significant headspace concentrations compared to those in the headspace of Group $2(P<0.05)$. Except for acetonitrile, a large increase in concentrations from ppbv to parts-per-million by volume (ppmv) scales of measurement was seen for methanol, propanol, ammonia, chloroform and formaldehyde. No formation of VOCs or DBPs occurred in Group 1 headspace, when chemomechanical preparation was not performed.

\section{Discussion}

The aim of this study was to investigate ex vivo the potential formation of VOCs and DBPs and the occurrence of periradicular extrusion in root canal disinfection procedures. A novel reproducible testing apparatus was fabricated to simulate the conditions of mechanical preparation and intracanal irrigation in a 'water-closed' apical system, to reflect high-compliance periapical tissue resistance to irrigant extrusion [19]. The model was designed to minimize the risk of fundamental methodological limitations from the absence of periradicular tissue pressure, such as overestimation of irrigant flow or extrusion, which could potentially lead to generation of false positive quantitative data [19]. The experimental endodontic procedures were performed by an accredited Specialist Endodontist, to ensure that chemomechanical preparation was performed under conditions of good clinical practice. The operational parameters of the adopted disinfection protocol, were subjected to conditions that predisposed for a minimum risk of extrusion. 
The results of this study showed that the chemomechanical preparation of infected root specimens in Groups 2 and 3 resulted in the formation and extrusion of VOCs and DBPs in a waterclosed periradicular space. When sterile saline was used as root canal irrigant, only low concentrations of VOCs and DBPs were detectable in the periradicular space, after chemomechanical preparation. The formation of VOCs in Group 2 is related to the metabolic activity of the growing biofilm within root canal specimens. Many studies have shown that SIFT-MS technology aids in the rapid detection of small quantities of a range of VOCs, as a means of monitoring the dynamics in bacterial cultures or biofilms, in real time [31-33].

The present work has shown that the concentrations of VOCs and DBPs presented a significant increase when $2.5 \% \mathrm{NaOCl}$ was used as the main root canal irrigant, which is in agreement with the results of a recent study [11]. A significant increase in compounds was evident, which are commonly present in biological media including acetone, acetic acid, methanol, propanol, acetaldehyde and ammonia $[11,28,30]$.

A significant increase in chloroform formation $(1.2 \pm 0.3 \mathrm{ppmv})$ in the periradicular space was evident in Group 3. Previous studies reported the formation of chloroform, following the interaction of $\mathrm{NaOCl}$ with endodontic biomaterials including dentine powder, pulp tissue fragments, planktonic multimicrobial suspensions, bovine serum albumin and their combinations $[10,11]$. In another study, the combined findings of bacterial inactivation and DBP formation confirmed that the break-down of bacterial cells provides organic precursors for DBP formation [34]. Anaerobic bacteria also form chloroform during their respiration and convert it to dichloromethane $[35,36]$. This evidence strongly supports the pathway for DBP formation from pure bacterial biomaterials [34]. An alternative pathway for the formation of chloroform may also derive from the interaction of $\mathrm{NaOCl}$ with acetone according to the historically known haloform reaction: $3 \mathrm{NaOCl}+\mathrm{C}_{3} \mathrm{H}_{6} \mathrm{O} \rightarrow \mathrm{CHCl}_{3}+2 \mathrm{NaOH}+\mathrm{NaOCOCH}_{3}$ [37].

The uptake of chloroform into blood circulation via periradicular extrusion and any relevant implications have not yet been examined in vivo. This VOC can also be absorbed into the body by inhalation, through the skin and by ingestion [38]. The United States Environmental Protection Agency (USEPA) has classified chloroform as a probable human carcinogen [38], but the World Health Organisation (WHO) has concluded that the weight of evidence suggests that chloroform does not have direct genotoxic potential [39]. 
The European Agency for Safety and Health at Work has established indicative occupational skin exposure limit values for chloroform at $10 \mathrm{mg} / \mathrm{m}^{3}$ or $2 \mathrm{mg} / \mathrm{L}$ per 8 working hours [40]. Chloroform is still used in endodontics as a solvent of root canal sealers and gutta-percha in cases of root canal retreatment as well as for the customisation of master gutta-percha cone during root canal obturation $[41,42]$. Despite the potentially serious concerns regarding its safety due to dental personnel inhalation exposure risks [43], previous risk assessment studies report that chloroform has no negative health effects under careful and controlled use $[44,45]$. However, considering that this work has indicated a new potential source of chloroform, further occupational risk assessment studies are required in dental surgeries, where large volumes of $\mathrm{NaOCl}$ are consumed for root canal treatments.

An unexpected finding was the formation of high concentrations of formaldehyde in Group 3, during the chemomechanical preparation with $\mathrm{NaOCl} 2.5 \%$ and EDTA $17 \%$. This finding has not been reported in dental literature before. The oxidation of EDTA via $\mathrm{NaOCl}$ has been reported, but not the mechanism for the production of formaldehyde, so this merits further investigation. Several studies have been performed to assess the antagonistic effects between $\mathrm{NaOCl}$ and EDTA, when used as root canal irrigants. In most of them, the residual free available content of $\mathrm{NaOCl}$ solutions was measured with iodometric titrations, when mixed with EDTA at different ratios and time intervals. The results showed that, due to an unspecified chemical reaction, the free available chlorine content is significantly reduced; hence, the direct mixture, or the intermittent use is not recommended due to an upcoming reduction in antimicrobial capacity of $\mathrm{NaOCl}[46,47]$. Chlorine gas formation was also detectable and the risks of occupational exposure have been highlighted [48-50]. The use of nuclear magnetic resonance analysis also confirmed that a chemical reaction between $\mathrm{NaOCl}$ and EDTA occurs, leading to $\mathrm{NaOCl}$ deactivation, slow oxidation of EDTA and progressive formation of unknown by-products [51].

To ensure that formaldehyde release was not associated with experimental bias, the $2.5 \% \mathrm{NaOCl}$ solution used in the present experiments was mixed with five different brands of commercially available $17 \%$ EDTA solutions for dental use, at 1:1 volume ratio, for 3min. SIFT-MS analysis confirmed the formation of high concentrations of formaldehyde varying from 1.2ppmv to 39ppmv. Visual assessment of the aliquots disclosed various findings such as gas and bubble formation, colour change into brown as well as milky shady appearance. Colour change may relate to different manufacturing processes in production of EDTA, additives or impurities that are unknown. 
Formaldehyde is a colorless, flammable gas at room temperature, has a pungent, distinct odor and may cause a burning sensation to the eyes, nose and lungs at high concentrations [52]. It is mainly used as a biocide in disinfection of equipment and fixation of tissue [52]. A study conducted in Canada found that formaldehyde levels as low as $0.046 p p m v$ were positively correlated with eye and nasal irritation in houses with urea-formaldehyde foam insulation [53]. In 1987, the U.S. Environmental Protection Agency (EPA) classified formaldehyde as a probable human carcinogen, under conditions of unusually high or prolonged exposure [52]. Since then, human clinical studies concluded that prolonged exposure to formaldehyde was associated with cancer of the nasopharynx and leukaemia [54-56]. The International Agency for Research on Cancer (IARC), the Department of Health and Human Services (DHHS) and the European Chemicals Agency recently classified formaldehyde as a human carcinogen $[57,58]$.

The ex vivo chemomechanical preparation of a single infected root canal with rotary files, $2.5 \%$ $\mathrm{NaOCl}$ and $17 \%$ EDTA resulted in apical extrusion of high concentrations of formaldehyde. SIFT-MS analysis disclosed the formation of average 10ppmv concentration of formaldehyde in periradicular space. Despite the fact that the measurable concentrations exceeded the safety thresholds, in reference to occupational and patient healthcare and safety, the results should be interpreted with caution. In this experimental set-up, one missing factor was the lack of circulation of the periradicular fluid, as a simulation of blood flow and circulation in human mandible or maxilla within cancellous bone vacuoles. Since the extruded chlorinated biomaterials remained static, the inadvertent extrusion of EDTA may have resulted in chemical production of formaldehyde in situ. In human body, where blood circulation is constant, it is less likely that such high concentrations may be formed. In addition, it should not be underestimated that formaldehyde can be metabolized as it is a normal component of blood. According to some studies, human body exposure to $2.4 \mathrm{mg} / \mathrm{m}^{3}$ formaldehyde did not increase the blood level and exposure to $0.5 \mathrm{mg} / \mathrm{m}^{3}$ did not result in an increase in urinary formate excretion due to rapid local metabolism $[59,60]$. However, these early pre-clinical findings disclosed high levels of this toxic compound and further clinical studies are required to investigate the formation of VOCs and especially formaldehyde in the apical tissues and the systemic blood circulation in patients undergoing root canal treatment.

From the results shown here, clinicians should also consider the verified interaction of $\mathrm{NaOCl}$ and EDTA, which leads to formation of formaldehyde in gaseous form. Therefore, the intermittent use 
of $\mathrm{NaOCl}$ and EDTA during irrigation should be totally aborted. Our findings further raise occupational hazard concerns, as the risk of inhalation of the forming aerosol in a dental surgery is present. The patient may be potentially exposed for one or two dental sessions, but the dentist and dental staff may inhale the volatile phase throughout their working days.

The Agency for Toxic Substances and Disease Registry (ATSDR) has established a chronic inhalation minimal risk level of $0.003 p p m v$ formaldehyde $\left(0.004 \mathrm{mg} / \mathrm{m}^{3}\right)$ based on respiratory effects in humans [61]. The Occupational Safety and Health Administration (OSHA) set a legal permissible exposure limit in the workplace of $0.75 p p m v$ formaldehyde in air averaged over an 8 -h time-weighted average work day [62]. A second permissible exposure limit in the form of a short-term exposure limit of 2ppmv, which is the maximum exposure allowed during a 15-min period [62]. The European Commission recently proposed new exposure limits for formaldehyde. An 8-h time weighted average exposure limit of $0.37 \mathrm{mg} / \mathrm{m}^{3}$ and a 15 -min short-term exposure limit of $0.738 \mathrm{mg} / \mathrm{m}^{3}$ is now under effect [58]. Therefore, further occupational risk assessments are required in dental settings to justify the risk of exposure in formaldehyde and various VOCs or DBPs.

Taking into consideration this new implication from the combined use of $\mathrm{NaOCl}$ and EDTA, it is essential to review the use of EDTA and its relevant concentration for the removal of the inorganic phase of the smear layer. Alternative chelating agents, such as citric acid, must be studied further, but subject to the induction of a potential strong acid-base reaction when mixed with $\mathrm{NaOCl}$. The current concept of continuous irrigation and chelation with the use of a single solution containing $\mathrm{NaOCl}$ and etidronic acid has showed promising results $[63,64]$. However, further investigation is required to justify the possibility of potential formation of other VOCs and DBPs.

\section{Conclusions}

Within the limitations of this ex vivo study, the mechanical preparation and irrigation of artificially infected root canals with rotary NiTi files, $2.5 \% \mathrm{NaOCl}$ and $17 \%$ EDTA resulted in the formation of toxic VOCs and DBPs in a water-closed periradicular space. The chemical interaction of $\mathrm{NaOCl}$ and EDTA resulted in the generation of high concentrations of formaldehyde. The formation of chloroform and formaldehyde indicate that risk assessment of the potential hazards to health should be carried out. 


\section{References}

[1] Wallace B, Purcell M, Furlong J. Total organic carbon analysis as a precursor to disinfection byproducts in potable water: oxidation technique considerations. J Envir Monit 2002;4:35-42.

[2] Khan MR, Wabaidur SM, Alothman ZA, Busquets R, Naushad M. Methods for the fast determination of bromate, nitrate and nitrite by ultra performance liquid chromatography-mass spectrometry and their monitoring in Saudi Arabian drinking water with chemometric data treatment. Talanta 2016;152:513520.

[3] Krasner WS. The formation and control of emerging disinfection by-products of health concern. Philos Trans Royal Soc 2009;367:4077-4095.

[4] Ashley DL, Blount BC, Singer PC, Depaz E, Wilkes C, Gordon S, Lyu C, Masters J. Changes in blood trihalomethane concentrations resulting from differences in water quality and water use activities. Arch Environ Occup Health 2005;60:7-15.

[5] Richardson SD, Plewa MJ, Wagner ED, Schoeny R, Demarini DM. Occurrence, genotoxicity, and carcinogenicity of regulated and emerging disinfection by-products in drinking water: a review and roadmap for research. Mut Res 2007;636:178-242.

[6] Villanueva CM, Cantor KP, Grimalt JO, Malats N, Silverman D, Tardon A, Garcia-Closas R, Serra C, Carrato A, Castaño-Vinyals G, Marcos R, Rothman N, Real FX, Dosemeci M, Kogevinas M. Bladder cancer and exposure to water disinfection by-products through ingestion, bathing, showering, and swimming in pools. Amer J Epidem 2006;165:148-156.

[7] Sedgley C. Root canal irrigation--a historical perspective. J Hist Dent 2004;52:61-5.

[8] Basrani B, Haapasalo M. Update on endodontic irrigating solutions. Endod Topics 2012;27:74-102.

[9] Haapasalo M, Qian W, Shen Y. Irrigation: beyond the smear layer. Endod Topics 2012;27:35-53.

[10] Varise TG, Estrela C, Costa Guedes DF, Sousa-Neto MD, Pécora JD. Detection of organochlorine compounds formed during the contact of sodium hypochlorite with dentin and dental pulp. Braz Dent $J$ 2014;25:109-116.

[11] loannidis K, Niazi S, Deb S, Mannocci F, Smith D, Turner C. Quantification by SIFT-MS of volatile compounds produced by the action of sodium hypochlorite on a model system of infected root canal content. PLoS One 2018;13:e0198649.

[12] Tanalp J, Güngör T. Apical extrusion of debris: a literature review of an inherent occurrence during root canal treatment. Int Endod J 2014;47:211-221.

[13] Hülsmann M, Rödig T, Nordmeyer S. Complications during root canal irrigation. Endod Topics 2009;16:27-63.

[14] Pashley EL, Birdsong NL, Bowman K, Pashley DH. Cytotoxic effects of $\mathrm{NaOCl}$ on vital tissue. J Endod 1985;11:525-8.

[15] Kerbl FM, DeVilliers P, Litaker M, Eleazer PD. Physical effects of sodium hypochlorite on bone: an ex vivo study. J Endod 2012;38:357-9.

[16] Siqueira JF Jr. Microbial causes of endodontic flare ups. Int Endod J 2003;36:453-63.

[17] Ng Y-L, Mann V, Rahbaran S, Lewsey J, Gulabivala K. Outcome of primary root canal treatment: systematic review of the literature - Part 2. Influence of clinical factors. Int Endod J 2008;41: 6-31.

[18] Torabinejad M, Handysides R, Khademi AA, Bakland LK. Clinical implications of the smear layer in endodontics: a review. Oral Surg Oral Med Oral Pathol Oral Radiol Endod 2002;94:658-666.

[19] Psimma Z, Boutsioukis C, Kastrinakis E, Vasiliadis L. Effect of needle insertion depth and root canal curvature on irrigant extrusion ex vivo. J Endod 2013;39:521-4. 
[20] Niazi SA, Clark D, Do T, Gilbert SC, Foschi F, Mannocci F, Beighton D. The effectiveness of enzymic irrigation in removing a nutrient-stressed endodontic multispecies biofilm. Int Endod $\mathrm{J}$ 2014;47:756-68.

[21] Dahlén G, Konradsson K, Eriksson S, Teanpaisan R, Piwat S, Carlén A. A microbiological study in relation to the presence of caries and calculus. Acta Odontol Scand 2010;68:199-206.

[22] Niazi SA, Clarke D, Do T, Gilbert SC, Mannocci F, Beighton D. Propionibacterium acnes and Staphylococcus epidermidis isolated from refractory endodontic lesions are opportunistic pathogens. $J$ Clin Microbiol 2010;48:3859-3869.

[23] Gmür R, Guggenheim B. Antigenic heterogeneity of Bacteroides intermedius as recognized by monoclonal antibodies. Inf Immun 1983;42:459-470.

[24] Lin J, Shen Y, Haapasalo M. A comparative study of biofilm removal with hand, rotary nickeltitanium, and self-adjusting file instrumentation using a novel in vitro biofilm model. $\mathrm{J}$ Endod 2013;39:658-63.

[25] Al Shahrani M, DiVito E, Hughes CV, Nathanson D, Huang GT. Enhanced removal of Enterococcus faecalis biofilms in the root canal using sodium hypochlorite plus photon-induced photoacoustic streaming: an in vitro study. Photomed Laser Surg 2014;32:260-6.

[26] Bhuva B, Patel S, Wilson R, Niazi S, Beighton D, Mannocci F. The effectiveness of passive ultrasonic irrigation on intraradicular Enterococcus faecalis biofilms in extracted single-rooted human teeth. Int Endod J 2010;43:241-50.

[27] Smith D, Španěl P. Selected ion flow tube mass spectrometry (SIFT-MS) for online trace gas analysis. Mass Spectrom Rev 2005;24:661-700.

[28] Španěl P, Smith D. Progress in SIFT-MS: breath analysis and other applications. Mass Spectrom Rev 2011;30:236-267.

[29] Španěl P, Smith D, Holland TA, AI Singary W, Elder JB, Analysis of formaldehyde in the headspace of urine from bladder and prostate cancer patients using selected ion flow tube mass spectrometry. Rapid Commun Mass Spectrom 1999;13:1354-1359.

[30] Turner C, Parekh B, Walton C, Španěl P, Smith D, Evans M. An exploratory comparative study of volatile compounds in exhaled breath and emitted by skin using selected ion flow tube mass spectrometry. Rapid Commun Mass Spectrom 2008;22:526-532.

[31] Storer MK, Hibbard-Melles K, Davis B, Scotter J. Detection of volatile compounds produced by microbial growth in urine by selected ion flow tube mass spectrometry (SIFT-MS). J Microbiol Meth 2011;87:111-3.

[32] Sovová K, Čepl J, Markoš A, Španěl P. Real time monitoring of population dynamics in concurrent bacterial growth using SIFT-MS quantification of volatile metabolites. Analyst 2013;138:4795-801.

[33] Chen NH, Djoko KY, Veyrier FJ, McEwan AG. Formaldehyde stress responses in bacterial pathogens. Front Microbiol 2016;7:257.

[34] Wang JJ, Liu X, Ngc TW, Xiao JW, Chow AT, Wong PK. Disinfection byproduct formation from chlorination of pure bacterial cells and pipeline biofilms. Wat Res 2013;47:e2701- e2709.

[35] Tang S, Edwards EA. Identification of Dehalobacter reductive dehalogenases that catalyse dechlorination of chloroform, 1,1,1-trichloroethane and 1,1-dichloroethane. Philos Trans R Soc Lond B Biol Sci 2013;1616:20120318.

[36] Jugder BA, Haluk E, Wong YK, Braidy N, Manefield M, Marquis CP, Lee M. Genomic, transcriptomic and proteomic analyses of Dehalobacter UNSWDHB in response to chloroform. Environ Microb Rep 2016;5:814-824.

[37] Reynold C, Fuson A, Bull B. The Haloform Reaction. Chem Rev 1934;15:275-309.

[38] U.S. Environmental Protection Agency's Integrated Risk Information System (IRIS) on Chloroform, https://cfpub.epa.gov/ncea/iris/iris documents/documents/subst/0025 summary.pdf/; 2001 [accessed 12 December 2017]. 
[39] World Health Organisation, http://www.who.int/ipcs/publications/cicad/en/cicad58.pdf/; 2004 [accessed 12 December 2017].

[40] Agency for Toxic Substances and Disease Registry,

https://www.atsdr.cdc.gov/toxprofiles/tp.asp?id=53\&tid=16; 1997 [accessed 12 December 2017).

[41] Martos J, Bassotto AP, González-Rodríguez MP, Ferrer-Luque CM. Dissolving efficacy of eucalyptus and orange oil, xylol and chloroform solvents on different root canal sealers. Int Endod $J$ 2011;44:1024-1028.

[42] Van Zyl SP, Gulabivala K, Ng YL. Effect of customization of master gutta-percha cone on apical control of root filling using different techniques: an ex vivo study. J Endod 2005;38:658-666.

[43] Allard U, Andersson L. Exposure of dental personnel to chloroform in root-filling procedures. Endod Dent Traumatol 1992;8:155-159.

[44] Margelos J, Verdelis K, Eliades G. Chloroform uptake by gutta-percha and assessment of its concentration in air during the chloroform-dip technique. J Endod 1996;22:547-550.

[45] Chutich MJ, Kaminski EJ, Miller DA, Lautenschlager EP. Risk assessment of the toxicity of solvents of gutta-percha used in endodontic retreatment. J Endod 1998;24:213-216.

[46] Clarkson RM, Podlich HM, Moule AJ. Influence of ethylenediaminetetraacetic acid on the active chlorine content of sodium hypochlorite solutions when mixed in various proportions. J Endod 2011;37:538-43.

[47] Krishnan U, Saji S, Clarkson R, Lalloo R, Moule AJ. Free active chlorine in sodium hypochlorite solutions admixed with octenidine, SmearOFF, Chlorhexidine, and EDTA. J Endod 2017;43:1354-1359.

[48] Baumgartner JC, Ibay AC. The chemical reactions of irrigants used for root canal debridement. J Endod 1987;13:47-51.

[49] Irala LED, Grazziotin-Soares R, Azevedo Salles A, et al. Dissolution of bovine pulp tissue in solutions consisting of varying $\mathrm{NaOCl}$ concentrations and combined with EDTA. Braz Oral Res 2010;24:271-6.

[50] Prado M, Santos Júnior H, Rezende CM, Pinto AC, Faria RB, Simão RA, Gomes BP. Interactions between irrigants commonly used in endodontic practice: a chemical analysis. J Endod 2013;39:50510.

[51] Grande NM, Plotino G, Falanga A, Pomponi M, Somma F. Interaction between EDTA and sodium hypochlorite: a nuclear magnetic resonance analysis. J Endod 2006;32:460-4.

[52] U.S. Environmental Protection Agency. Integrated Risk Information System (IRIS) on formaldehyde, https://www.epa.gov/sites/production/files/2016-09/documents/formaldehyde.pdf/; 1999 [accessed 8 May 2019].

[53] Broder I, Corey P, Brasher P, Lipa M, Cole P. Formaldehyde exposure and health status in households. Environ Health Perspect 1991;95:101-4.

[54] Hauptmann M, Lubin JH, Stewart PA, Hayes RB, Blair A. Mortality from lymphohematopoietic malignancies among workers in formaldehyde industries. J Nat Cancer Inst 2003;95:1615-1623.

[55] Hauptmann M, Stewart PA, Lubin JH, et al. Mortality from lymphohematopoietic malignancies and brain cancer among embalmers exposed to formaldehyde. J Nat Cancer Inst 2009;101:1696-1708.

[56] Beane Freeman L, Blair A, Lubin JH, et al. Mortality from lymphohematopoietic malignancies among workers in formaldehyde industries: The National Cancer Institute Cohort. J Nat Cancer Inst 2009;101:751-761.

[57] International Agency for Research on Cancer (IARC) monographs on the evaluation of carcinogenic risks to humans,

https://monographs.iarc.fr/wp-content/uploads/2018/09/ClassificationsAlphaOrder.pdf/; 2012

[accessed 22 January 2019]. 
[58] European Chemicals Agency. Formaldehyde and formaldehyde releasers - Strategy for future work, https://echa.europa.eu/documents/10162/13641/formaldehyde review report en.pdf/551df4a228c4-2fa9-98ec-c8d53e2bf0fc/; 2018 [accessed 6 December 2018).

[59] Kimbell JS et al. Dosimetry modeling of inhaled formaldehyde: binning nasal flux predictions for quantitative risk assessment. Toxicol Sci 2001;64:111-121.

[60] Kimbell JS et al. Dosimetry modeling of inhaled formaldehyde: comparisons of local flux predictions in the rat, monkey, and human nasal passages. Toxicol Sci 2001;64:100-110.

[61] Agency for Toxic Substances and Disease Registry. Public Health Statement. Formaldehyde CAS\# 50-00-0, https://www.atsdr.cdc.gov/substances/toxsubstance.asp?toxid=39/; 2008 [accessed 14 December 2018].

[62] Occupational Safety and Health Administration. Formaldehyde Standard 29 CFR 1910.1048 https://www.osha.gov/OshDoc/data General Facts/formaldehyde-factsheet.pdf/; 2011 [accessed 17 December 2018].

[63] Lottanti S, Gautschi H, Sener B, Zehnder M. Effects of ethylenediaminetetraacetic, etidronic and peracetic acid irrigation on human root dentine and the smear layer. Int Endod J 2009;42:335-43.

[64] Arias-Moliz MT, Ordinola-Zapata R, Baca P, Ruiz-Linares M, Ferrer-Luque CM. Antimicrobial activity of a sodium hypochlorite/etidronic acid irrigant solution J Endod 2014;40:1999-2002.

\section{Figures and figure legends}

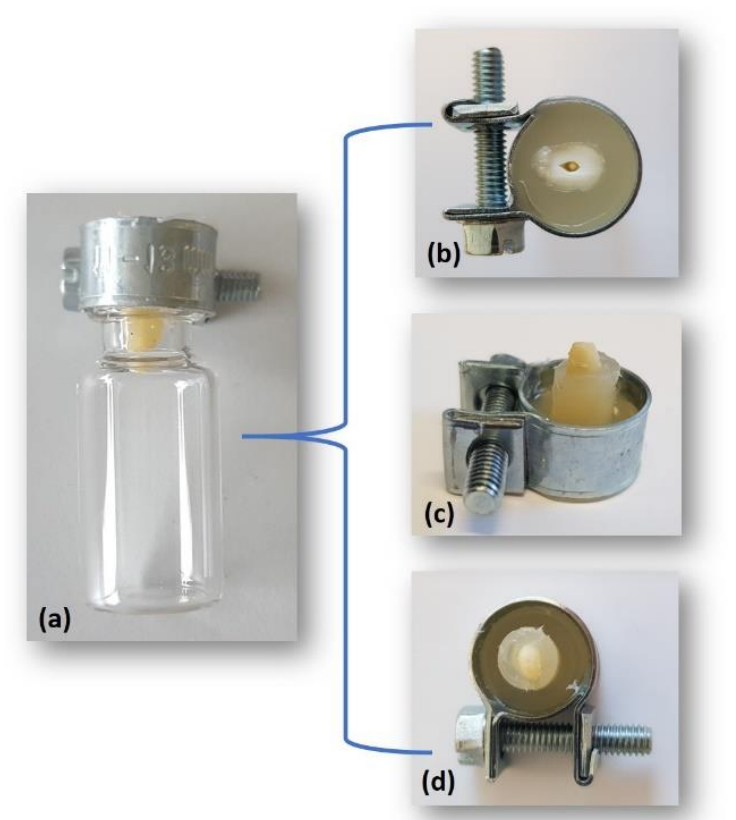


Figure 1. Infected tooth-model testing apparatus. (a) Adjustment of clamp diameter to glass bottle open end. (b) Coronal view of clamp-silicon index. (c) Lateral view of clamp silicon index. (d) Apical view of clamp-silicon index.

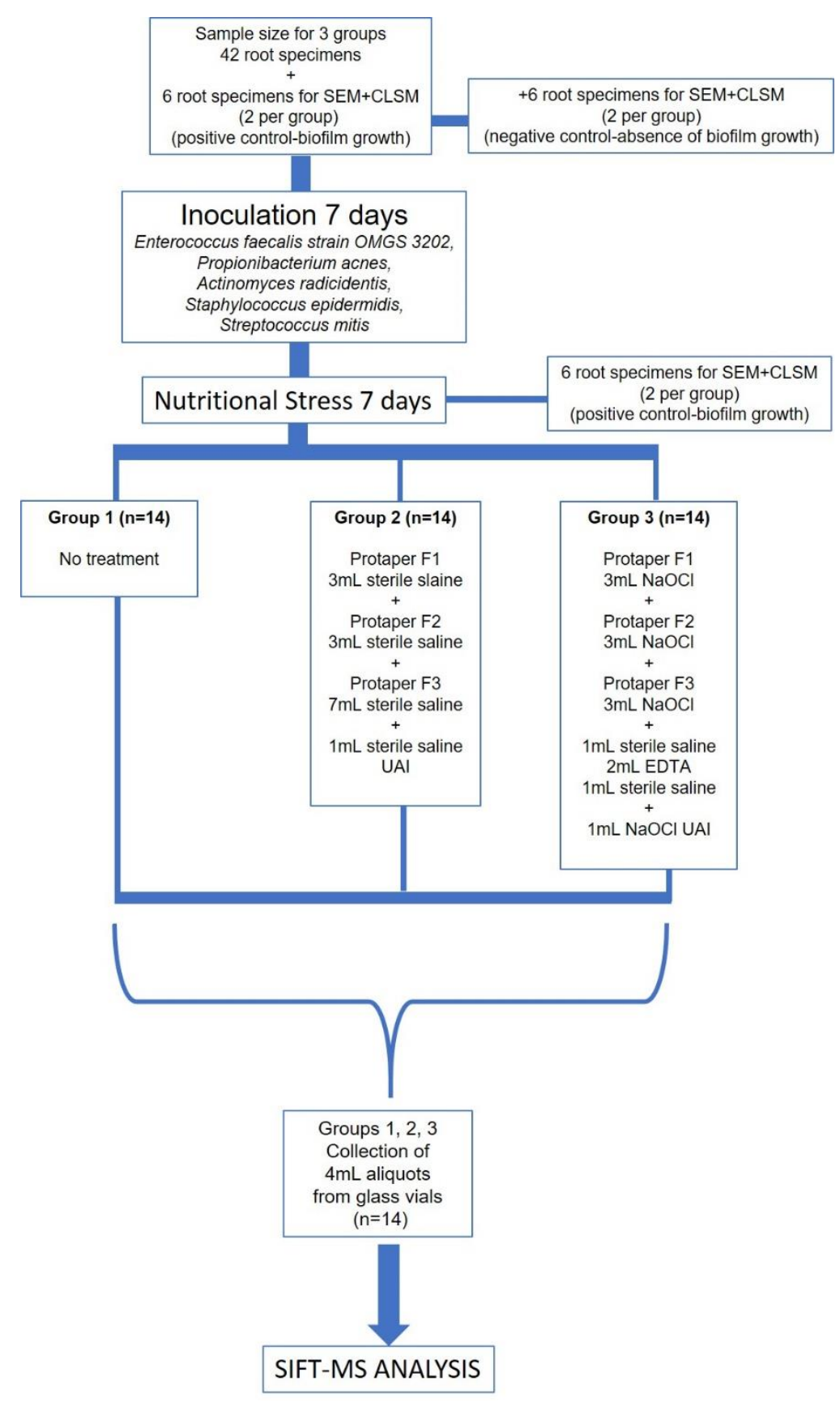

Figure 2. Flow-chart of designed experimental procedures, including sample size calculation, allocation of root specimens, biofilm growth, protocols of root canal chemomechanical preparation and SIFT-MS analysis. 


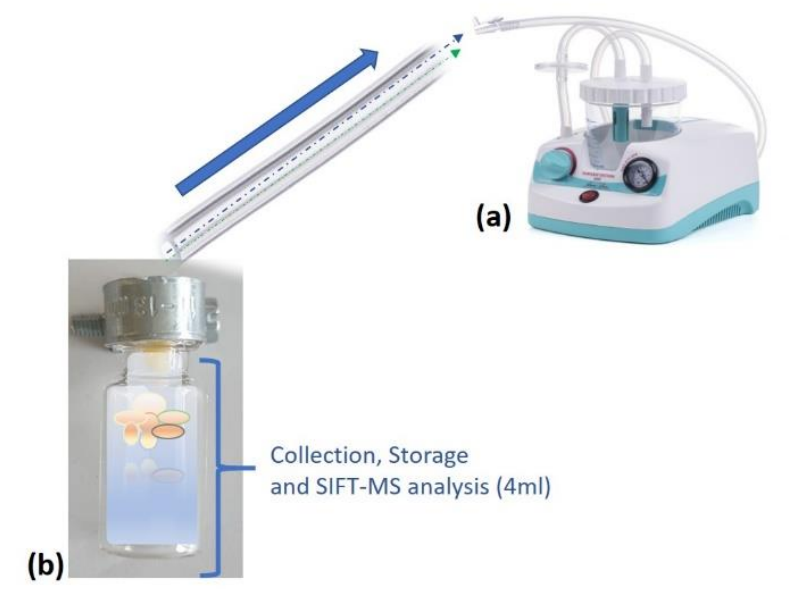

Figure 3. Experimental set-up of root canal irrigation and aspiration. (a) Application of portable medical suction. (b) Water-closed apical system filled with sterile ultrapure water.
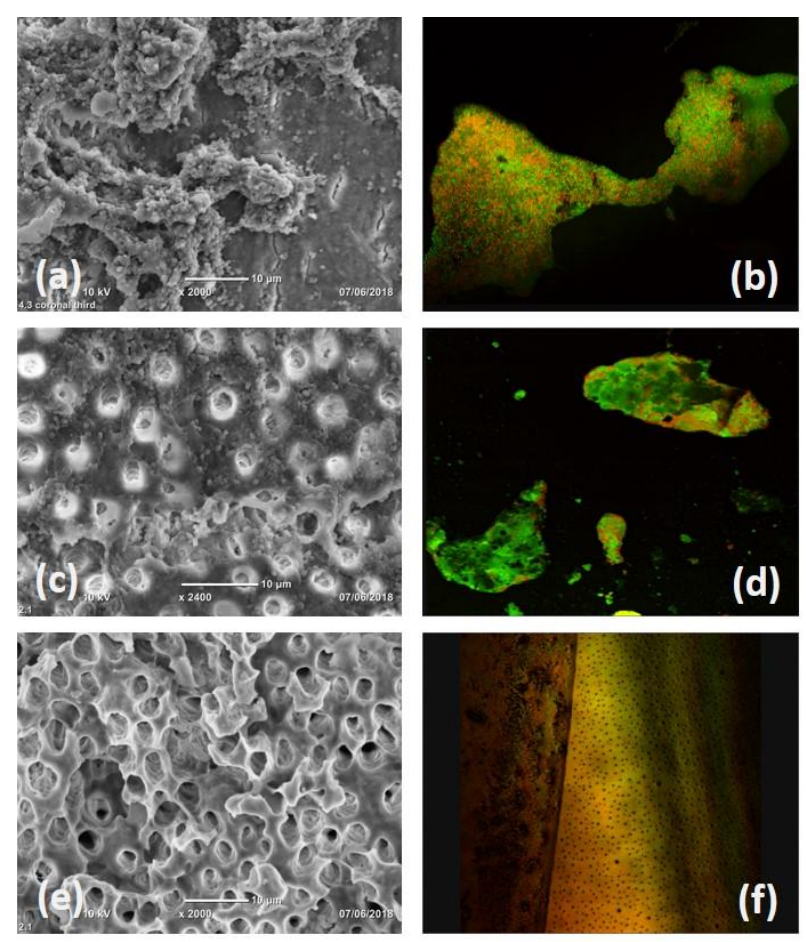

Figure 4. SEM and CLSM examination of infected and non-infected tooth specimens. $(a, b)$ Biofilm growth attached in intra-radicular dentine surface, facing main root canal lumen; (c, d) Biofilm growth within dentine tubules. $(e, f)$ Sterile, patent and bacteria-free dentine tubules. 


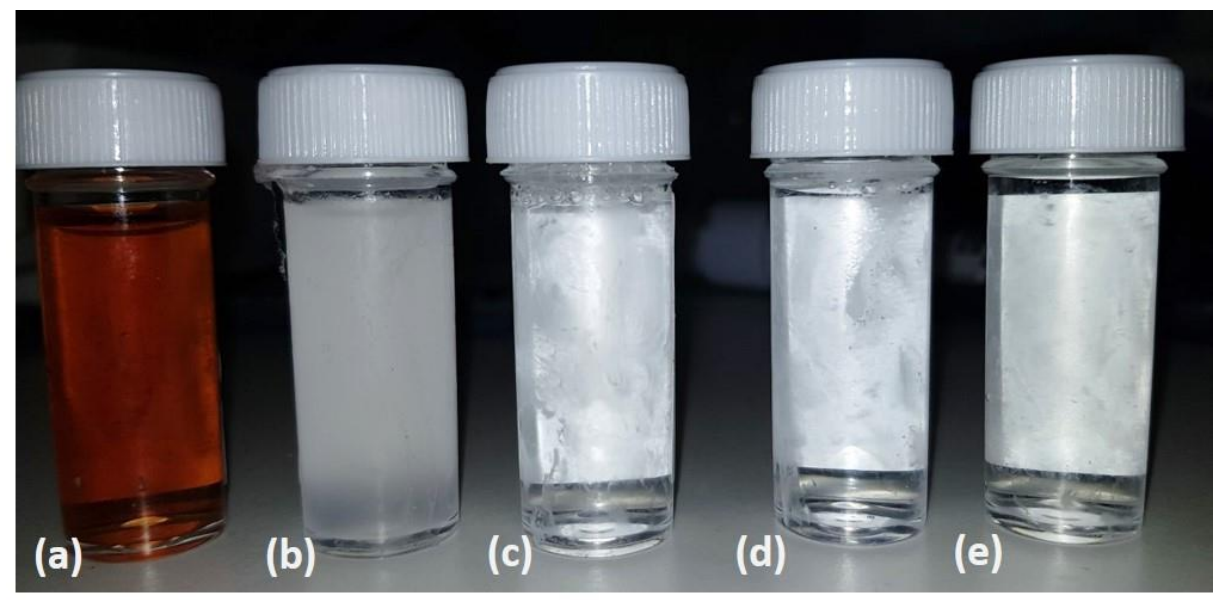

Figure 5. Visual assessment of the interaction of $2.5 \% \mathrm{NaOCl}$ and different brands of commercially available $17 \%$ EDTA solutions for endodontic use. (a) Schottlander 17\% EDTA + 2.5\% NaOCl. (b) Endo-solution $17 \%$ EDTA + 2.5\% NaOCl. (c) SmearClear 17\% EDTA + 2.5\% NaOCl. (d) Tgcleanser 17\% EDTA + 2.5\% NaOCl. (e) Pulpdent $17 \%$ EDTA $+2.5 \% \mathrm{NaOCl}$.

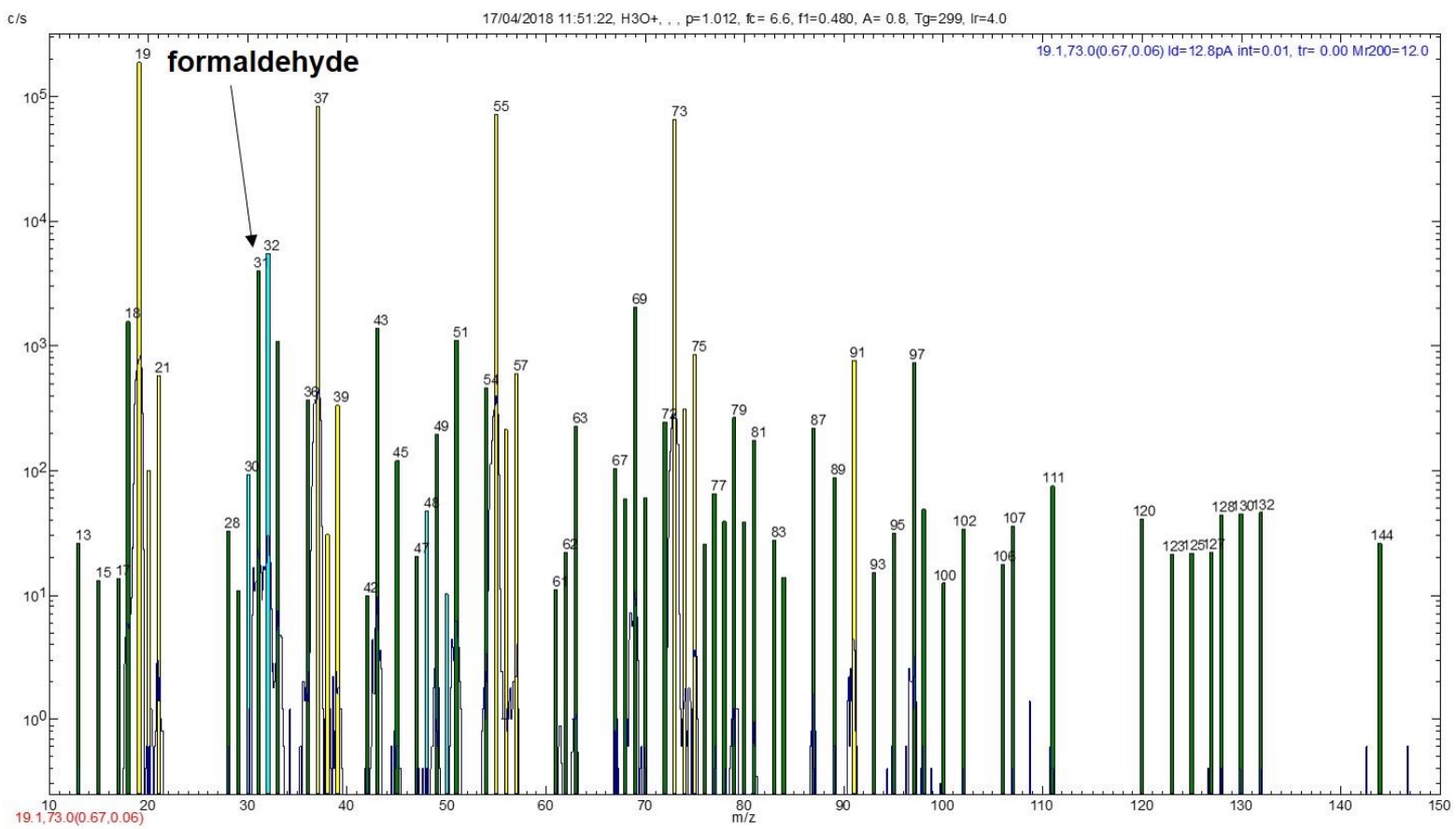

Figure 6. $\mathrm{H}_{3} \mathrm{O}+$ spectrum of Group 3 aliquot sample (irrigation with $2.5 \% \mathrm{NaOCl}+17 \% \mathrm{EDTA}$ ) obtained from periradicular space in air. Ion indicating formaldehyde at $\mathrm{m} / \mathrm{z} 31$ is shown on the spectrum. 


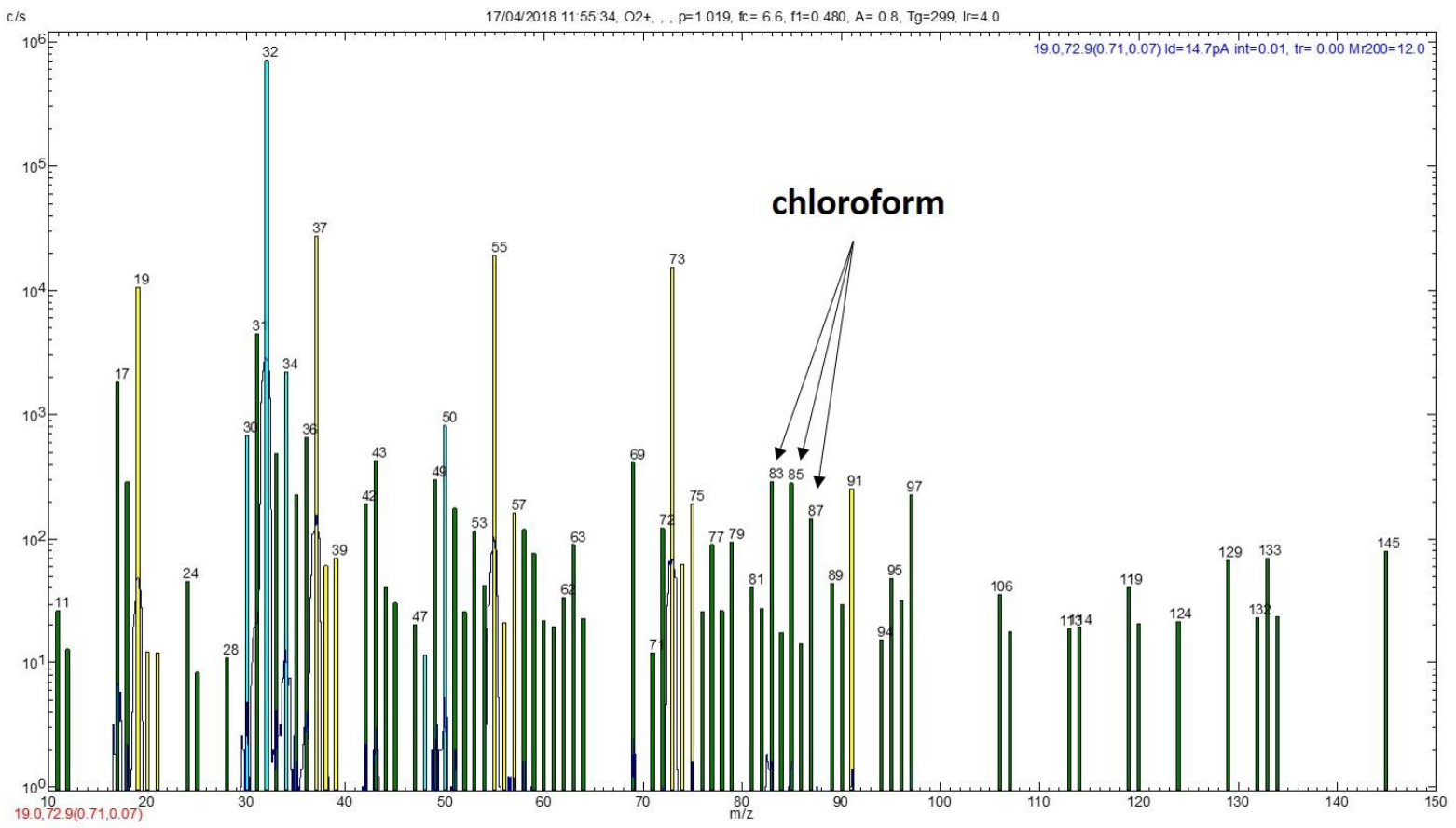

Figure 7. $\mathrm{O}_{2}+$ spectrum of Group 3 aliquot sample (irrigation with $2.5 \% \mathrm{NaOCl}+17 \%$ EDTA) obtained from periradicular space in air. Ions at $\mathrm{m} / \mathrm{z} 83,85,87$ indicating chloroform is shown on the spectrum. 
Table 1. Formaldehyde release following SIFT-MS analysis of $2.5 \% \mathrm{NaOCl}$ chemical interaction with $17 \%$ EDTA of five different brands.

\begin{tabular}{|c|c|c|}
\hline $\begin{array}{l}\text { Product Brand / } \\
\text { MANUFACTURER }\end{array}$ & $\begin{array}{l}\text { IRRIGANT INTERACTION } \\
\text { (3min, 1:1 volumes) }\end{array}$ & $\begin{array}{c}\text { FORMALDEHYDE } \\
\text { RELEASE (ppb.V) } \\
\text { Mean (SD) }\end{array}$ \\
\hline \multirow{2}{*}{$\begin{array}{l}\text { Schottlander EDTA } \\
\text { (Schottlander \& Davis, } \\
\text { Letchworth Garden } \\
\text { City, UK) }\end{array}$} & $17 \%$ EDTA & $155(21)$ \\
\hline & $17 \%$ EDTA + $2.5 \% \mathrm{NAOCl}$ & $11710(830)$ \\
\hline \multirow{2}{*}{$\begin{array}{l}\text { Pulpdent EDTA } \\
\text { (PULPDENT }^{\mathrm{TM}} \text {, } \\
\text { (Watertown, } \\
\text { Massachusetts, USA) }\end{array}$} & $17 \%$ EDTA & $25(4.9)$ \\
\hline & $17 \%$ EDTA $+2.5 \% \mathrm{NAOCl}$ & $1197(330)$ \\
\hline \multirow{2}{*}{$\begin{array}{l}\text { TGcleanser } \\
\text { (TGdent, Westminster, } \\
\text { London, UK) }\end{array}$} & $17 \%$ EDTA & $17.5(5.7)$ \\
\hline & $17 \%$ EDTA $+2.5 \% \mathrm{NAOCl}$ & 333 (39) \\
\hline \multirow{2}{*}{$\begin{array}{l}\text { SmearClear (Kerr TM, } \\
\text { Orange, California, } \\
\text { USA) }\end{array}$} & $17 \%$ EDTA & $66(17.6)$ \\
\hline & $17 \%$ EDTA + $2.5 \% \mathrm{NAOCI}$ & $39160(3130)$ \\
\hline \multirow{2}{*}{$\begin{array}{l}\text { ENDO-Solution } \\
\text { (CERKAMED, Stalowa } \\
\text { Wola, Poland) }\end{array}$} & $17 \%$ EDTA & $36(9.0)$ \\
\hline & $17 \%$ EDTA + $2.5 \% \mathrm{NAOCI}$ & $16600(2800)$ \\
\hline
\end{tabular}


Table 2. Mean (SD) concentrations (ppb.V) of VOCs and DBPs after SIFT-MS analysis of aliquots obtained from periradicular space.

\begin{tabular}{|c|c|c|c|}
\hline $\begin{array}{l}\text { Aliquots in } \\
\text { periradicular space } \\
(4 \mathrm{ml})\end{array}$ & $\begin{array}{c}\text { Group } 1 \\
\text { No endodontic } \\
\text { intervention } \\
\quad(n=14)\end{array}$ & $\begin{array}{c}\text { Group } 2 \\
\text { Chemomechanical } \\
\text { preparation with } \\
\text { Distilled Water } \\
(\mathrm{n}=14)\end{array}$ & $\begin{array}{c}\text { Group } 3 \\
\text { Chemomechanical } \\
\text { preparation with } 2.5 \% \\
\mathrm{NaOCl} \text { and final flush } \\
\text { with } 17 \% \text { EDTA } \\
(n=14)\end{array}$ \\
\hline Acetone & N/D & $7.32(7.23)^{a}$ & $27.18(14.86)$ * \\
\hline Acetic Acid & $\mathrm{N} / \mathrm{D}$ & 49.36 (23.61) & $144.71(57.27)$ * \\
\hline Methanol & N/D & $96.1(54.15)$ & $4903.37(2813.75)$ * \\
\hline Ethanol & N/D & $139.81(70.21)$ & $202.44(80.12)$ \\
\hline Propanol & N/D & $17.71(24.35)^{b}$ & $2462.22(1459.26)$ * \\
\hline Acetaldehyde & N/D & $17.64(6.72)$ & $440.43(138.27)^{*}$ \\
\hline Acetonitrile & N/D & $5.86(3.35)$ & $53.79(29.08)$ * \\
\hline Ammonia & N/D & $416.21(93.26)$ & $3620.71(1851.73)$ * \\
\hline Chloroform & N/D & $52.07(9.49)$ & $1266.64(340.49)$ * \\
\hline Formaldehyde & N/D & 80.78 (51.71) & $10167.94(3388.51)$ * \\
\hline
\end{tabular}

N/D: non-detectable; ${ }^{\text {: }} 4$ samples presented 0 values; ${ }^{b}: 6$ samples presented 0 values; * : statistically significant increase in concentration of each volatile compound in Group 3 compared to Group $2(P<0.05)$. 